\title{
Determinantes das taxas de lucro e de acumulação no Brasil: os fatores estruturais da deterioração conjuntural de 2014-2015
}

\author{
Determinants of the rates of profit and \\ accumulation in Brazil: the structural factors \\ of the cyclical deterioration of 2014-2015
}

MIGUEL ANTONIO PINHO BRUNO* ANTONIO RICARDO DANTAS CAFFE**

RESUMO: As tendências das taxas de lucro e de acumulação são indicadores fundamentais nas análises das crises econômicas. Essas variáveis respondem pelas trajetórias de crescimento econômico e são condicionadas pela distribuição funcional da renda. A deterioração da conjuntura macroeconômica a partir de 2014, no Brasil, tem sido frequentemente atribuída pela ortodoxia a erros inerentes à chamada "nova matriz de política econômica". Entretanto, o exame das taxas de lucro e de acumulação, imediatamente após o impacto da crise americana em 2009, aponta para a reafirmação de fatores estruturais, característicos da economia brasileira atual, que não poderiam ser superados por medidas anticíclicas. PALAVRAS-CHAVE: Taxa de lucro; acumulação de capital; desenvolvimento; política econômica; ciclos e crises.

ABSTRACT: The trends in profit and accumulation rates are key indicators in the analysis of economic crises. These variables account for the trajectories of economic growth and they are conditioned by the functional distribution of income. The deterioration of the macroeconomic conjuncture from 2014, in Brazil, has often been attributed, by mainstream analysis, to the errors inherent in the so-called "new matrix of economic policy". However, the analysis of profit and accumulation rates, immediately after the impact of the US crisis in Brazil, in 2009, shows the existence of structural factors that are characteristic of the current

\footnotetext{
* Escola Nacional de Ciências Estatísticas do Instituto Brasileiro de Geografia e Estatística (ENCE-IBGE), Rio de Janeiro, Brasil. E-mail: miguel.pbruno@gmail.com.

* Professor pesquisador do Programa de Pós-Graduação em Economia da Universidade Federal da Bahia-PPGE/UFBA, Brasil. (5/3/1964 - 28/4/2018). E-mail: ricardo.caffe@gmail. Submetido: 27/Setembro/2016; Aprovado: 12/Maio/2017.
} 
Brazilian economy, which could not be overcome by countercyclical fiscal and monetary policies.

KEYWORDS: Profit rate; capital accumulation; development; economic policy; cycles and crises.

JEL Classification: E1; E12; E25; E32; O4; O47.

\section{INTRODUÇÃO}
"Há sempre uma alternativa à propriedade de ativos de capital real, notadamente, a propriedade de moeda e dívidas."

(John Maynard Keynes, General Theory, 2016, p.192)1

A dinâmica da taxa de lucro é um dos principais fatores determinantes da taxa de acumulação de capital e, consequentemente, do ritmo de crescimento econômico. Seu comportamento tendencial reflete as condições de produção e de demanda em seus impactos de médio e longo prazos.

O objetivo básico deste artigo é avaliar em que medida a deterioração da conjuntura macroeconômica brasileira, a partir de 2014, pode ser atribuída a erros de política econômica ou a tentativa de se instituir uma "nova matriz de política econômica", supostamente de acordo com os preceitos desenvolvimentistas ou novo-desenvolvimentistas. Estudos recentes, com metodologias microeconômicas, no nível dos balanços empresariais (Rocca e Santos JR., 2014) ou com dados das contas nacionais (Miebach, 2015), também detectaram queda da taxa de lucro bruto e, consequentemente, do investimento em capital fixo das empresas, antes da deterioração da conjuntura macroeconômica em 2014-2015.

A presente análise utiliza dados das contas nacionais brasileiras e calcula as taxas de lucro bruto macroeconômico e de lucro bruto empresarial para o período 1995-2015, com frequência trimestral e, posteriormente, com séries anualizadas. Os resultados mostram queda significativa da rentabilidade real do capital e da taxa de acumulação, que se revelam anteriores à deterioração da conjuntura macroeconômica em 2014. A explicação mais plausível é a de que as quedas das taxas de lucro e de acumulação de capital resultam de condições estruturais de produção e de demanda que caracterizam a economia brasileira desde a consolidação de seu novo padrão de inserção internacional a partir dos anos 1990. Esse padrão acelerou o processo de desindustrialização, levando ao predomínio das commodities na pauta de exportações, o que elevou a vulnerabilidade externa, dada à inelasticidade-renda desse tipo de produto.

Argumenta-se que as principais dificuldades da economia brasileira decorrem de fatores estruturais, ou seja, são expressões das especificidades de seu regime de

\footnotetext{
${ }^{1}$ Tradução livre do original inglês pelos autores.
} 
acumulação subordinado às finanças e não de tentativas de mudanças pontuais em determinados aspectos do chamado "tripé" de política macroeconômica (câmbio flutuante, metas de inflação e de superávits fiscais primários). Nesse contexto, políticas contracíclicas podem apenas minimizar temporariamente a deterioração da conjuntura, mas não são capazes de suprimir as tendências de bloqueio do investimento produtivo que a financeirização pela renda de juros, por sua lógica e natureza, necessariamente impõe. Quando o valor das exportações de commodities declinou e as respostas governamentais limitaram-se a estímulos à demanda interna, o déficit em transações correntes e a deterioração da conjuntura vão comprometer a eficácia das políticas de desonerações fiscais, impossibilitando a retomada do investimento.

O artigo está estruturado da seguinte maneira. Além dessa introdução, a segunda seção apresenta os principais fatos estilizados da evolução das taxas de lucro e de acumulação no Brasil, comparativamente ao caso dos EUA, epicentro da crise de 2008. A terceira seção analisa os determinantes estruturais das taxas de lucro empresarial e da taxa de acumulação, explicitando a influência da distribuição funcional da renda, ora em favor dos salários, ora em favor da renda financeira apropriada pelo capital bancário e rentista. A quarta seção tenta mostrar que a taxa de acumulação não é apenas influenciada pela rentabilidade real do capital. Numa economia financeirizada, a alternativa de alocação em ativos líquidos e de baixo risco está sempre presente, mas competindo vantajosamente com as alocações diretamente produtivas em capital fixo. Então, mesmo que as taxas de lucro estejam em patamares elevados, comparativamente à média internacional, a taxa de investimento pode permanecer muito baixa, mantendo a economia em trajetórias de baixo e instável crescimento econômico. O texto termina com a quinta seção, que reúne os principais resultados encontrados.

\section{LUCRO E ACUMULAÇÃO: PRINCIPAIS FATOS ESTILIZADOS}

A taxa geral de lucro bruto ou taxa de lucro macroeconômico é definida pela razão entre a massa de lucros brutos (das empresas não financeiras e financeiras) e o estoque bruto de capital fixo produtivo para o total da economia brasileira. Este último considera o volume total de máquinas e equipamentos, instalações e as construções não residenciais ${ }^{2}$. Para o cálculo da taxa de lucro bruto das empresas não financeiras ou taxa de lucro empresarial considera-se a massa de lucros brutos líquida dos fluxos de juros pagos ao setor bancário-financeiro. Essas duas definições buscam separar os lucros operacionais, obtidos em atividades diretamente

\footnotetext{
${ }^{2}$ As construções residenciais não devem ser incluídas no capital fixo produtivo. Este último deve considerar apenas o capital fixo das empresas e as infraestruturas distributivas e de circulação da produção (estradas, portos, aeroportos, ferrovias, armazéns etc.). Mas o estoque de capital fixo do governo é incluído no estoque de capital fixo produtivo total.
} 
produtivas (por parte das empresas não financeiras) daqueles obtidos na circulação financeira sem impactos significativos sobre o crescimento do estoque de capital fixo produtivo, isto é, sobre a taxa de acumulação de capital.

A evolução da taxa de lucro bruto (r) na economia brasileira pode ser observada, comparativamente com o caso norte-americano, epicentro da crise de 2008, no Gráfico 1 a seguir. Observe-se que, apesar da subida da taxa de lucro brasileira em 2010, é nítida sua entrada em uma trajetória de acentuado declínio a partir de 2011. Ao mesmo tempo, a taxa norte-americana permanece mais estável, inclusive ultrapassando os níveis da brasileira em 2014.

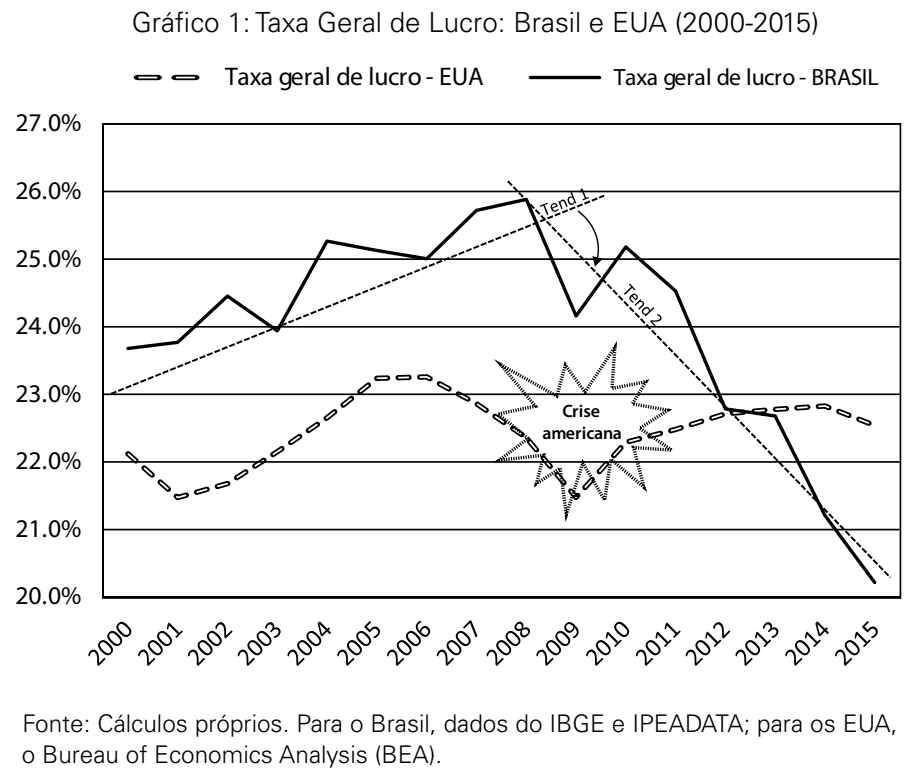

A queda tendencial da taxa de lucro bruto macroeconômico é um indicador clássico de crise estrutural. Então o caso brasileiro precisa ser analisado com cuidado quanto às condições estruturais de produção e de demanda e não como resultado necessário de desvios na política do "tripé”, sacralizada pela Macroeconomia ortodoxa como a única correta disponível aos policy makers de Brasília. Se adotarmos o ponto de vista regulacionista ${ }^{3}$, a política econômica é apenas o "volante"; o "motor" da economia é seu regime de acumulação, com suas estruturas institucionais vigentes: o padrão de inserção internacional, a importância da acumulação industrial; o tipo de regime monetário-financeiro e as especificidades da relação capital-trabalho assalariado e das relações Estado-economia. Nesse contexto, a política econômica deve ser compatível com as regularidades macroeconômicas induzidas por essa arquitetura institucional.

\footnotetext{
${ }^{3}$ Refere-se à Escola francesa da Regulação.
} 
O Gráfico 2 mostra uma tendência de crescimento da taxa de acumulação de capital até 2011 e depois nítida queda. Expressão da entrada da economia brasileira em uma nova fase de dificuldades. Já a taxa de acumulação da economia dos EUA, embora permaneça, em média, a metade da taxa brasileira, parece ter entrado numa trajetória de expansão.

Gráfico 2: Taxa de Acumulação de Capital Fixo Produtivo: Brasil E EUA (2000-2014)

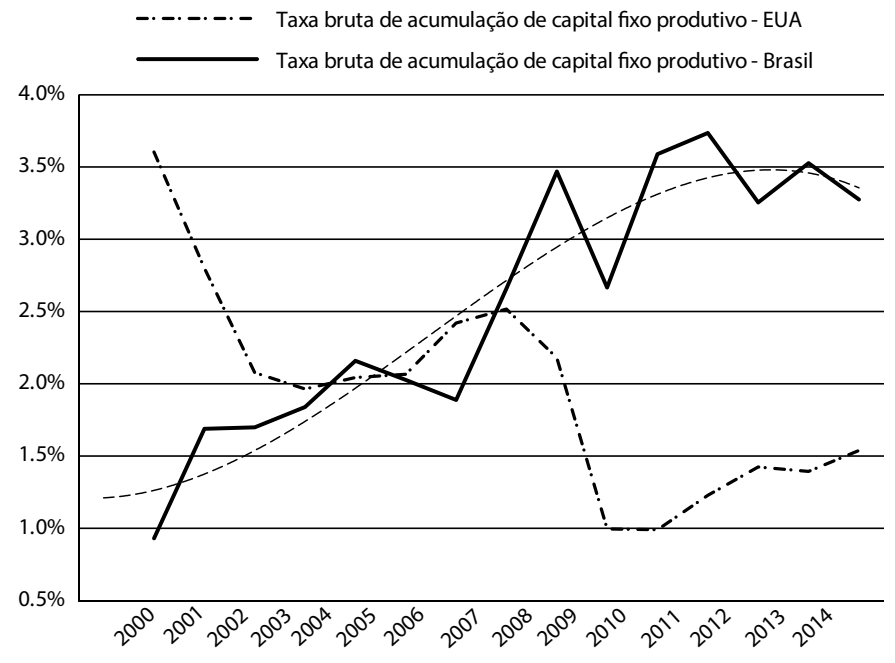

FONTE: Cálculos próprios. Para o Brasil, dados IBGE e IPEADATA; para os EUA, o Bureau of Economics Analysis (BEA).

Esses fatos estilizados demandam uma análise mais detida, para se investigar o que está por trás dessas tendências macroeconômicas.

\section{OS DETERMINANTES DAS TAXAS DE LUCRO EMPRESARIAL E DE ACUMULAÇÃO}

Uma das características mais importantes da economia brasileira nas duas últimas décadas tem sido a predominância da acumulação rentista-financeira, derivada das elevadas taxas reais de juros vigentes. Nesse contexto, o sistema de metas de inflação, cuja racionalidade implica a prática de aumentos das taxas oficiais de juros como instrumento supostamente eficaz de controle inflacionário, possui efeitos colaterais adversos sobre as estruturais produtivas, notadamente às industriais. Esses efeitos são decorrentes do elevado peso da renda de juros cujo maior beneficiário é o setor bancário-financeiro.

Essa é a problemática básica dos estudos sobre o fenômeno da financeirização das economias no século XXI (Palley, 2007; Stockhammer, 2004) e das especificidades que assume no caso brasileiro (Bruno, 2007; Bruno et al., 2011). A financeirização da economia brasileira é singular em muitos aspectos. Diferentemente do 
que ocorre em países desenvolvidos onde as taxas de juros são muito baixas ou até negativas, as taxas praticadas no Brasil penalizam o investimento produtivo, reduzindo o lucro empresarial e as taxas de crescimento econômico.

\section{A taxa de lucro empresarial: principais determinantes macroeconômicos}

Considerando o produto $Y$ pela ótica dos rendimentos e a distribuição primária da renda, $Y=\Pi^{e}+F+W$, onde $\Pi^{e}$ é a massa de lucros brutos empresariais, $F$ é o fluxo total de renda financeira apropriada pelo sistema bancário-financeiro, famílias detentoras de capital e demais empresas e $W$ é a massa salarial, tem-se que:

$$
\frac{\Pi}{Y}=1-\frac{F}{Y}-\frac{W}{Y}
$$

Seja $\pi^{e}=1-\varphi-w^{s}$, sendo $\pi^{e}=\frac{\Pi}{Y}$ a participação dos lucros brutos empresariais no PIB (profit share), $\varphi=\frac{F}{Y}$ é a participação da renda financeira no produto total (rentier share) e $w^{S}=\frac{W}{Y}$ é a participação dos salários (wage share).

A taxa de lucro bruto empresarial $\left(r^{e}\right)$ é definida pela razão entre os lucros empresariais $\Pi$ e o estoque total de capital fixo produtivo $K$, defasado em um período:

$$
r^{e}=\frac{\Pi}{K_{-1}}
$$

Mas, $W=\omega . N$, onde $\omega$ é o salário médio real e $N$ o nível geral de emprego, implica que $w^{s}=\frac{W}{Y}=\frac{\omega}{\rho_{n}}$, ou seja, a parcela salarial é matematicamente idêntica à razão entre o salário médio real e a produtividade do trabalho, $\rho_{n}$.

Este fato tem implicações fundamentais para a recuperação da participação dos salários no PIB brasileiro. Se os salários crescerem no mesmo ritmo da produtividade, a parcela salarial, já muito baixa na economia brasileira, permaneceria no mesmo patamar. Para que cresça, é necessário que os salários reais cresçam acima dos ganhos de produtividade, pelo menos por um período suficiente. Substituindo-se a parcela salarial por sua relação equivalente, $\frac{\omega}{\rho_{n}}$, e dividindo-se ambos os lados pelo estoque de capital fixo produtivo ${ }^{4} K$, chega-se a $\frac{\Pi}{K_{-1}}=\rho_{k}\left[1-\frac{\omega}{\rho_{n}}-\varphi\right]$ que é uma formulação geral ou macroeconômica para a taxa de lucro bruto empresarial:

$$
r^{e}=\rho_{k}\left[1-\frac{\omega}{\rho_{n}}-\varphi\right]
$$

Embora algebricamente simples, essa equação reúne variáveis que são fundamentais ao processo de acumulação de capital porque expressam as condições estruturais em que se move a distribuição funcional da renda e o conflito distributivo subjacente à relação capital-trabalho.

Observe-se que na equação 3 o termo entre colchetes $\left[1-\frac{\omega}{\rho_{n}}-\varphi\right]$ expressa o

\footnotetext{
${ }^{4}$ Estoque de máquinas, equipamentos e construções não residenciais.
} 
impacto da distribuição funcional da renda na determinação da taxa de lucro em-

presarial. A razão $\frac{\omega}{\rho_{n}}$ traduz os efeitos do conflito distributivo entre capital e trabalho assalariado, enquanto $\varphi$ expressa os efeitos da rentier share no processo de determinação da taxa de lucro empresarial $r$.

Consequentemente, o crescimento do salário médio real acima do crescimento da produtividade do trabalho e/ou da produtividade do capital tende a deprimir a lucratividade empresarial. Mas quando a rentier share avança sobre o produto, a taxa de lucro empresarial também declina se não houver compensações advindas dos ganhos de produtividade ou de reduções do salário médio real.

Com os dados das contas nacionais do Brasil obterve-se o Gráfico 3 que mostra como evoluíram, em índice dos valores, os determinantes da taxa de lucro, segundo a equação 3 . As seguintes conclusões podem ser extraídas: a) a taxa de lucro empresarial atingiu seu ponto de máximo em 2009 (113,7) para em seguida entrar numa trajetória de rápido declínio, juntamente com a produtividade do capital, até o final das séries, em 2015; b) a produtividade do trabalho, embora crescente, permaneceu abaixo do crescimento do salário médio real, o que explica o avanço da wage share; c) este fato é reforçado pelo declínio da rentier share, até 2012, expressa pela variável $\varphi$; d) a partir de $2014, \varphi$ volta a crescer, expressando o aumento da parcela do excedente econômico apropriada pelo setor bancário-financeiro e rentistas, sob a forma de renda de juros.

\section{As políticas anticíclicas e a deterioração da conjuntura}

Embora possam ter atenuado os efeitos contracionistas dos impactos da crise de 2008 no Brasil, as políticas contracíclicas implementadas pelo governo (basicamente, expansão do crédito direcionado e desonerações fiscais) não foram capazes de conter a deterioração da conjuntura derivada do fim do boom dos preços das commodities. Como no plano interno a economia mantinha-se numa trajetória persistente de desindustrialização, o maior dinamismo do mercado interno provocado pela elevação dos salários reais não foi capaz de compensar a queda das exportações brasileiras a partir de 2012. Um dos resultados diretos foi o declínio das taxas de lucro e de acumulação de capital que se pôde constatar na seção anterior.

Nesse ambiente macroeconômico, com taxas de lucro em queda e de juros em elevação, políticas de isenções fiscais não surtiriam os efeitos esperados pelo governo, como ficou patente em 2015. Provavelmente, as isenções foram absorvidas na quitação de dívidas e na tentativa de preservar margens mínimas de lucro que permitissem a sobrevivência empresarial. Em face da incerteza crescente, não haveria motivo suficiente para expandir as atividades através de novos investimentos em ampliação da capacidade produtiva. Isso explicaria a desaceleração da economia decorrente da queda do investimento e do enfraquecimento da demanda agregada. 


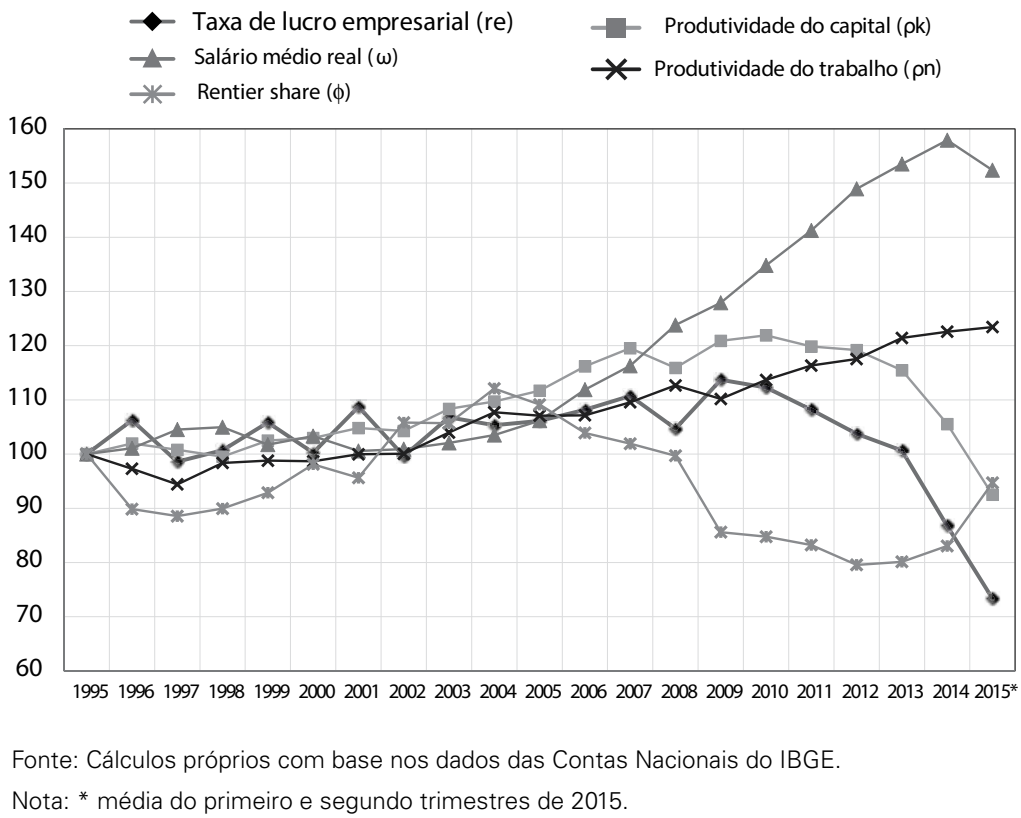

O Gráfico 3 apresenta a evolução de cada uma das variáveis determinantes da taxa empresarial de lucro, na economia brasileira: as produtividades do trabalho e do capital, o salário médio real e a rentier share (participação da renda de juros no produto). Destaque-se que a partir de 2013, a rentier share entra em uma trajetória de rápida expansão, refletindo os aumentos das taxas oficiais de juros promovidos pelo governo e a nova fase de reafirmação da hegemonia da alta finança ante o Estado brasileiro. A política de juros altos torna as quedas da taxa de lucro e da produtividade do capital ainda mais intensa, como pode ser observado nesse mesmo ano. O salário médio real interrompe sua trajetória de crescimento com uma queda brusca em 2015.

\section{A financeirização da economia: efeitos atenuados no período 2004-2010, mas não eliminados}

O fenômeno da financeirização tem sido objeto de análise tanto no Brasil quanto no exterior. Seus efeitos estão já documentados numa vasta literatura empírica, baseada tanto em análises históricas quanto em comparações internacionais. Por questão de espaço e objeto, não serão aprofundadas todas as implicações da financeirização, mas somente destacadas as especificidades do caso brasileiro.

Os trabalhos empíricos sobre esse problema macroeconômico são unânimes 
em reconhecer que a financeirização reduz as taxas de crescimento econômico porque provoca o declínio das taxas de lucro empresariais e de acumulação de capital fixo. Em economias não sujeitas a esse processo, as taxas de lucro e de acumulação compartilham tendência comum de evolução uma vez que a maior rentabilidade dos capitais nos setores diretamente produtivos, comparativamente às alocações financeiras, promove o investimento. ${ }^{5}$

Para esta análise, foram utilizadas duas definições para a taxa de financeirização. A primeira corresponde à razão entre o volume total de ativos financeiros não-monetários e o estoque total de capital fixo produtivo (taxa de financeirização -1). Trata-se, portanto, de uma relação entre duas variáveis-estoque. A segunda é a razão entre o fluxo agregado de renda financeira e o estoque total de ativos fixos produtivos (taxa de financeirização-2).

O Gráfico 4 é um diagrama de dispersão onde se pode constatar a correlação inversa entre a taxa de financeirização- 1 e a taxa de acumulação de capital fixo produtivo. O coeficiente de correlação de -0,6 é estatisticamente significativo. Como era de se esperar, à medida que a alocação financeira avança como proporção do estoque de capital, o investimento produtivo declina, porque a financeirização eleva a um paroxismo a preferência pela liquidez dos detentores de capital e, notadamente no caso brasileiro, a renda de juros gerada pela detenção dos títulos públicos compete vantajosamente com a rentabilidade do capital nas atividades diretamente produtivas.

Uma outra maneira de se interpretar esse fenômeno consiste em se considerar que a financeirização provoca substituição de poupança produtiva (recursos não consumidos que são alocados na formação bruta de capital empresarial, criando ativos novos) por poupança improdutiva (quando os recursos disponíveis são alocados nas transferências de propriedade de ativos já existentes e, portanto, sem criar ativos novos) $)^{6}$. Por esta razão, o período 2004-2011, de maior dinamismo da economia brasileira foi também aquele em que a rentier share declinou, provocando queda da taxa de financeirização com o consequente aumento da taxa de acumulação produtiva de capital.

\footnotetext{
${ }^{5}$ As séries das taxas de lucro macroeconômico e de acumulação de capital fixo produtivo devem, em geral, ser cointegradas na conceituação econométrica já que, em economias não-financeirizadas, essas variáveis devem compartilhar uma tendência comum de evolução. No entanto, os processos de financeirização desconectam essas séries que passam a seguir trajetórias relativamente autônomas ou até divergentes.

${ }^{6}$ As definições de poupança produtiva e de poupança improdutiva são as propostas em AGLIETTA (1995).
} 


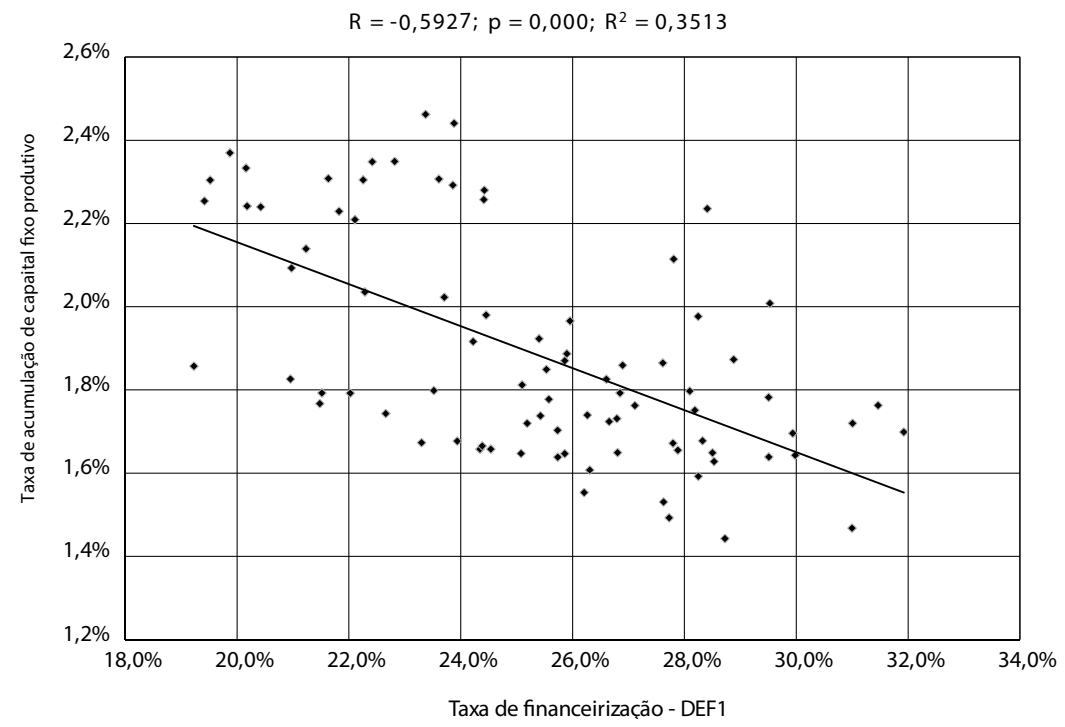

Fonte: Cálculos próprios com base nos dados do IBGE e IPEADATA.

Recorrendo à Definição 2, baseada na renda de juros, a correlação negativa e estatisticamente significativa entre a taxa de financeiriazação e a parcela investida dos lucros empresariais no Gráfico 5 também evidencia o caráter bloqueador da financeirização sobre a formação bruta de capital fixo. Em outros termos, a financeirização reduz a parcela dos lucros empresariais alocada em investimento; e esse fenômeno não pode ser eliminado, apenas atenuado por políticas de estímulos ao crescimento econômico por parte do Estado ou pela melhora do ambiente internacional, por exemplo, no que concerne às exportações das commodities brasileiras. Trata-se, portanto, de uma característica estrutural da economia brasileira que, para ser removida, exige mudanças institucionais profundas, notadamente quanto à forma de inserção do Brasil no cenário internacional e quanto às formas de relacionamento do setor bancário-financeiro com o setor produtivo. Uma condição fundamental é a reversão do processo de desindustrialização que responde pelos baixos ganhos de produtividade, característicos desse tipo de regime de acumulação. Mas isso pressupõe um ambiente macroeconômico compatível com o desenvolvimento industrial, notadamente no que concerne à vigência de taxas de juros em níveis próximos aos padrões internacionais e um regime cambial que possibilite taxas de câmbio competitivas. Condições muito difíceis de serem alcançadas sob o tipo de liberalização financeira que o país instituiu desde os anos 1990 e que impede o Estado brasileiro de dispor de maior controle sobre a determinação das taxas de juros e de câmbio, variáveis-chave para a eficácia de uma política industrial. 
Gráfico 5: Taxa de Financeirização - Definição 2

e Proporção do Lucro Bruto Empresarial Alocada em Capital Fixo Produtivo (1995-2015)

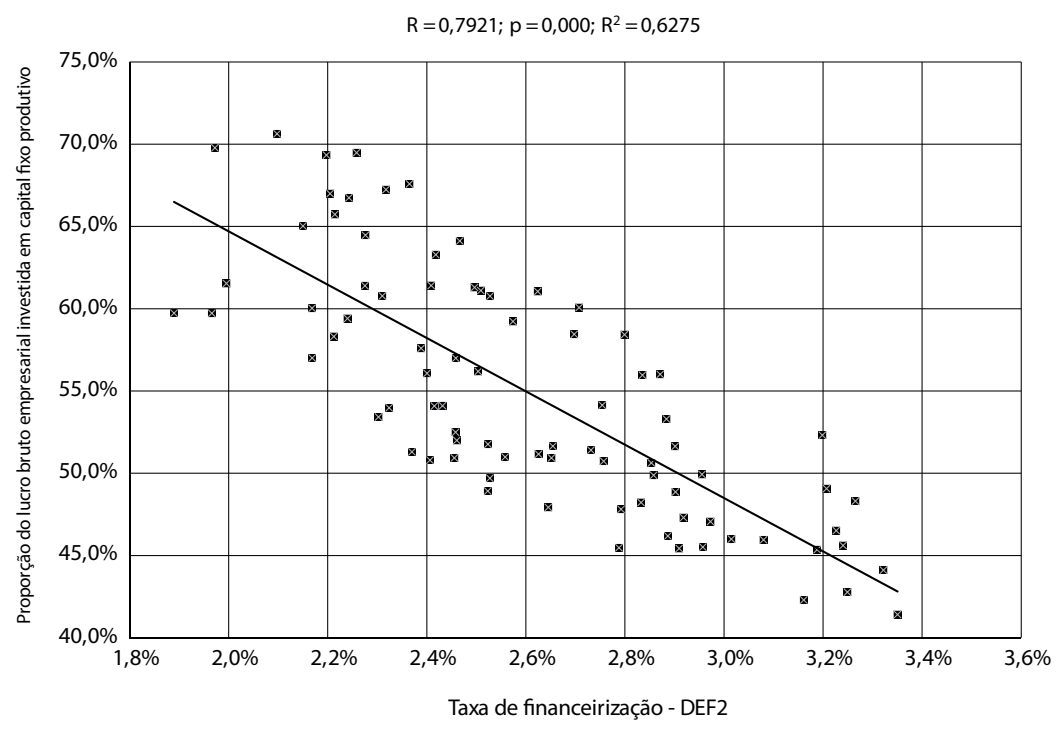

Fonte: Cálculos próprios com base nos dados do IBGE e IPEADATA.

A análise consistente da deterioração conjuntural a partir de 2014 deve incluir os fatores contracionistas endógenos decorrentes da financeirização, agora tornados mais explícitos e mais fortes em razão das medidas recessivas de austeridade fiscal implementadas pelo governo em 2015. Se o caráter bloqueador da financeirização sobre o crescimento econômico é estrutural, sua interação com um programa de ajuste fiscal de natureza deliberadamente recessiva torna ainda mais intensa a queda do nível de atividade que já ocorreria se a economia e o Estado não estivessem subordinados aos interesses da acumulação rentista-patrimonial.

\section{A parcela salarial entrará em declínio tendencial?}

Por seus impactos na formação da taxa geral de lucro, a distribuição funcional da renda tem sido uma variável fundamental nas análises das crises econômicas. As participações dos salários no PIB brasileiro e americano encontram-se no Gráfico 6. Quando se observa o comportamento da wage share na economia dos EUA, no período anterior à crise de 2008, constata-se sua tendência de declínio. O mesmo fenômeno é destacado pela literatura acerca da grande crise dos anos 1930, com epicentro também nesse país. No caso brasileiro, observa-se tendência oposta, com a wage share crescendo de 2004 até 2014. 


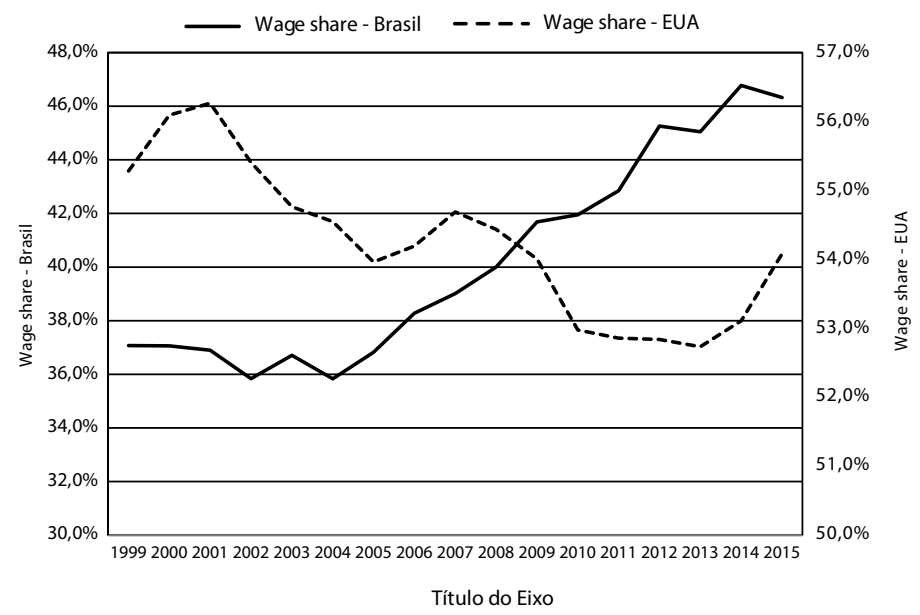

Fonte: Cálculos próprios para o Brasil, IBGE e IPEADATA; para os EUA, o Bureau of Economic Analysis (BEA).

Esse crescimento da parcela salarial foi um importante fator que favoreceu a expansão econômica, mesmo sob taxas moderadas de crescimento. No entanto, a partir de 2014, observa-se a entrada em um período de queda da wage share que certamente terá impactos negativos sobre o nível de atividade, uma vez que a conjuntura recessiva provoca contração do salário médio real e aumento das taxas de desemprego, numa conjuntura internacional incapaz de promover as exportações de commodities em um ritmo compensador.

Tal como reconheceram Keynes e Kalecki, a ambiguidade do rendimento salarial deverá entrar em cena, ou seja, como o salário é simultaneamente um custo de produção e principal fator de demanda nas economias capitalistas atuais, que são necessariamente estruturadas em sociedades salariais, não há garantias de que a recuperação no curto prazo da rentabilidade empresarial pela redução dos salários e a elevação do desemprego seja suficiente para compensar a queda da demanda efetiva resultante. A saída poderia ser pelas exportações brasileiras. Mas como, se a pauta de exportações é predominantemente de commodities, por natureza, renda inelástica, precisamente numa conjuntura internacional marcada pela desaceleração da China?

\section{A TAXA DE ACUMULAÇÃO E O INVESTIMENTO PRODUTIVO}

A taxa de acumulação de capital fixo produtivo é a variável-chave para explicar a dinâmica do crescimento econômico, mas ela não depende apenas da taxa de lucro. Esta pode estar em nível elevado sem, contudo, motivar o crescimento da taxa de acumulação. Este tem sido o caso da economia brasileira e das demais economias sujeitas ao fenômeno da financeirização. Em geral, para toda economia, quanto maior a alocação produtiva dos capitais, maiores tendem a ser as taxas de crescimento do 
PIB. Entretanto, numa economia financeirizada, as alternativas de alocação em ativos financeiros concorrem vantajosamente, em termos de liquidez e rentabilidade, com as imobilizações de capital nas atividades diretamente produtivas.

Seja a taxa de acumulação dada pela razão entre o fluxo de investimento em capital fixo produtivo e o estoque de capital no período t-1, $g=\frac{I N V}{K_{-1}}$. Considere-se a taxa de lucro empresarial dada pela razão $r^{e}=\frac{\Pi^{e}}{K_{-1}}$. Se dividirmos $g$ por $r^{e}$, chegaremos à proporção investida do lucro bruto, $\frac{g}{r}=\frac{I N V}{\Pi^{e}}$. Isolando a taxa de acumulação $g$, tem-se que:

$$
g=\left(\frac{I N V}{\Pi^{e}}\right) r^{e}
$$

Denominando-se a proporção investida do lucro $\frac{I N V}{\Pi}$, por $\psi$, e convertendo-se em taxas de variação chega-se a:

$$
\dot{g}=\dot{\gamma}+\dot{r}^{e}
$$

A equação (5) mostra que a dinâmica da taxa de acumulação de capital fixo produtivo depende tanto do crescimento da taxa de lucro $\dot{r}$, quanto das decisões empresariais em favor das alocações diretamente produtivas, isto é, do aumento da proporção investida do lucro empresarial $\dot{\gamma}$ : Mesmo que $r e$ já esteja em nível elevado, caso da economia brasileira, as alocações em ativos fixos produtivos podem declinar pela preferência das empresas e detentores de capital por alocações financeiras. E é exatamente isto o que o processo de financeirização institui e reproduz no plano macro, micro e dos setores econômicos. Na medida em que este fenômeno eleva a um paroxismo a preferência pela liquidez dos tomadores das decisões cruciais de investimento, ele reduz o fator $\gamma$ e mantém baixa ou estagnante a taxa de acumulação produtiva, reduzindo o ritmo de crescimento econômico.

Gráfico 7: Brasil: Proporção do Lucro Alocada em Formação Bruta de Capital Fixo (1991-2015)

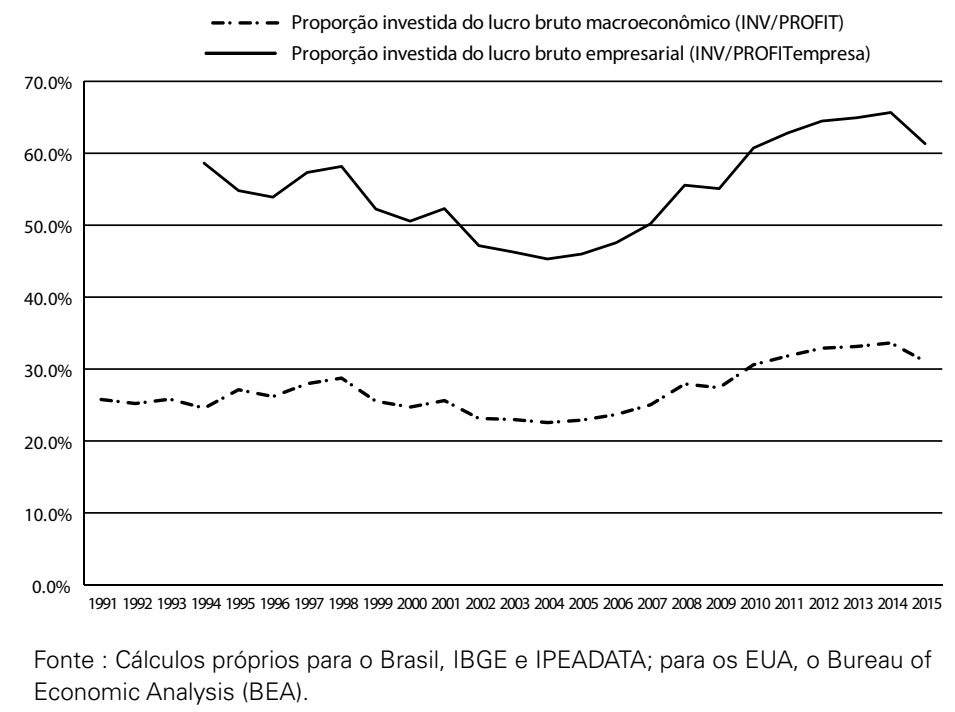


O Gráfico 7 mostra as proporções investidas do lucro bruto macroeconômico e do lucro bruto empresarial para a economia brasileira. No caso brasileiro, os aumentos das proporções investidas do lucro foram impulsionados tanto por fatores internos (melhoria da distribuição pessoal e funcional da renda; elevação do salário mínimo, aumento das transferências sociais, expansão das operações de crédito à produção e ao consumo) quanto externos (alta demanda pelas commodities brasileiras, notadamente, por parte da China).

Entretanto, a redução da influência positiva desses fatores sobre a performance macroeconômica brasileira reafirmará o caráter bloqueador da financeirização pela renda de juros sobre a acumulação produtiva. Em consequência, a expansão das alocações financeiras em detrimento da formação bruta de capital fixo das empresas se afirmaria nesse contexto em seus objetivos defensivos em face da deterioração conjuntural. Essa é uma das razões para a ineficácia das políticas governamentais de desonerações fiscais e demais medidas de reativação da economia por estímulos ao investimento e à demanda. Como vimos mais acima, as empresas do setor produtivo já haviam entrado em uma trajetória de rápido declínio da taxa de lucro empresarial decorrente de causas estruturais. Em consequência, dada a queda da demanda efetiva, as desonerações fiscais tornaram-se ineficazes para elevar a taxa de investimento e provavelmente foram usadas para quitar fornecedores e manter margens mínimas de rentabilidade.

$\mathrm{O}$ argumento anterior vem se apoiando em evidências que a literatura internacional reconhece como um fenômeno que muitos países da OCDE experimentaram desde os anos 1980. A relação virtuosa entre acumulação e investimento foi substituída por uma configuração atualmente marcada por conflitos que se originam na esfera distributiva, conhecida por investment-profit puzzle ${ }^{7}$. O persistente declínio da acumulação de capital tem sido acompanhado pela tendência ao aumento das taxas de lucro e da parte do lucro macroeconômico na renda (profit share). Os modelos pós-keynesianos tradicionais de crescimento e distribuição supunham até então, através de fatos estilizados, que altas taxas de acumulação podiam ser explicadas por altas taxas de lucro, num ciclo sustentável de expansão. O período de crise nessas circunstâncias é caracterizado pela queda das taxas de acumulação e de lucro, em conformidade com a abordagem original de Marglin \& Bhaduri (1991).

Nessa análise clássica, inspirada no declínio da Golden Age ou dos Trente Glorieuses $^{8}$, uma maior lucratividade é identificada como condição prévia para a retomada do investimento e do crescimento econômico nas economias desenvolvidas. Dois requisitos fundamentais encontrados foram o reconhecimento da necessidade de aumento da lucratividade real e da extrema conveniência de tornar a acumulação independente da lucratividade. Naquele contexto histórico, o declínio

\footnotetext{
${ }^{7}$ Ver a esse respeito, Van Treeck (2008).

${ }^{8}$ Período de forte crescimento econômico que marcou o pós-Segunda Guerra, conhecido na literatura regulacionista como o período de vigência dos regimes de acumulação fordistas (1945-1975).
} 
da profit-share teve um impacto negativo sobre a taxa de lucro, sob a perspectiva dos custos. Em consequência, a frustração das expectativas empresariais sobre a lucratividade futura contraiu o ímpeto da acumulação, contribuindo para a queda da taxa de lucro realizada e, consequentemente, para a entrada das economias em trajetórias de crescimento lento e instável.

A trajetória divergente entre lucro e acumulação observada na atualidade vai desencadear uma mudança nas previsões feitas com base nessas interpretações tradicionais de existência de uma correlação positiva entre essas duas variáveis fundamentais. Tornou-se necessário considerar-se os impactos da financeirização sobre a determinação da acumulação e da poupança empresarial. Consequentemente, a desconexão entre lucratividade e acumulação, uma vez operada pelos regimes dominados pelas finanças, realiza o que anteriormente se esboçava apenas como possibilidade teórica. De modo mais preciso, a financeirização pode desempenhar o papel de tornar a lucratividade independente da acumulação 9 . A busca de revalorização dos capitais por canais financeiros leva a uma crescente substituição do investimento (produtivo) como fonte de lucros macroeconômicos, tal como ficou patente ao longo das últimas décadas nos EUA.

A expansão da profit share e da rentier share não estimularam a acumulação e o crescimento econômico e, nem mesmo, a elevação do padrão médio de vida dos norte-americanos. A experiência do "novo boom econômico" constituiu uma breve exceção dos regimes de crescimento impulsionados pelas finanças, apesar dos sinais de sua recuperação mais recente. A ruptura do nexo investimento-lucro, a nível internacional, pode então incluir o caso brasileiro. Como consequência, existe a possibilidade das séries representativas do lucro e do investimento macroeconômicos apresentarem quebras estruturais. Assim sendo, a abordagem desenvolvida por Pesaran, Shin e Smith (2001), a qual propõe a utilização do teste de fronteira, torna-se indicada para situações onde não há certeza se os regressores são estacionários em tendência ou em primeiras diferenças. Desse modo, pode ser verificado se existe alguma evidência confortando uma relação de longo prazo dada pela cointegração entre as variáveis incluídas na equação (2) (Ver Apêndice I). Parte-se, desse modo, da estratégia empírica proposta pela metodologia do modelo Autorregressivo com Defasagens Distribuídas (ARDL) que, finalmente, pode ser estimado com base nas seguintes equações:

$$
\operatorname{LTXACUM}_{t}=\alpha_{1}+\sum_{i=1}^{p} \delta_{1 i} \operatorname{LTXACUM}_{t-i}+\sum_{i=0}^{p} \beta_{1 i} \text { LTXPFEMP }_{t-1}+\sum_{i=0}^{p} \theta_{1 i} L_{t-1}+\mu_{t}
$$

\footnotetext{
${ }^{9}$ Marglin e Bhaduri (1991, p. 35) de modo quase premonitório indicam que, "O crescimento impulsionado pelo lucro, a longo prazo, pode voltar a ser viável, mas a transição vai certamente exigir uma gestão ativa da demanda, presumivelmente uma possibilidade somente realizável após uma reforma exitosa do sistema financeiro internacional. [...]. Na verdade, em nossa opinião os elementos essenciais de qualquer alternativa de esquerda para políticas do mainstream para restaurar o crescimento são: $1^{\circ}$ ) reconhecer a necessidade presente de lucratividade, $2^{\circ}$ ) reconhecer a conveniência de tornar a acumulação independente da lucratividade em última instância, e $3^{\circ}$ ) estabelecer uma ponte entre ambas".
} 
Como os dados são trimestrais, um desfasamento máximo $(p)$ de ordem 4 é selecionado para a equação (5), de acordo com Pesaran e Shin (1998). A especificação de uma dinâmica ARDL de curto prazo pode ser derivada com base numa representação de correção de erros a partir de forma:

$$
\text { LTXACUM }_{t}=\alpha_{2}+\sum_{i=1}^{p} \delta_{1 i} \Delta \text { LTXACUM }_{t-i}+\sum_{i=0}^{p} \beta_{1 i} \Delta \text { LTXPFEMP }_{t-1}+\sum_{i=0}^{p} \theta_{1 i} \Delta L H_{t-1}+\mu_{t}
$$

O símbolo $\Delta$ é o operador da diferença e o termo de correção de erros, $E C M_{t}$, definido como:

$$
E C M_{t}=\operatorname{LTXACUM}_{t}-\left(\alpha_{1}+\sum_{i=1}^{p} \delta_{1 i} L_{T X A C U M_{t-i}}+\sum_{i=0}^{p} \beta_{1 i} \operatorname{LTXPFEMP}_{t-i}+\sum_{i=0}^{p} \theta_{1 i} L H_{t-1}\right)
$$

Todos os coeficientes da equação (12) são aqueles relacionados com as dinâmicas de curto prazo, indicando o modelo de convergência para o equilíbrio na sequência de choques do sistema. E o símbolo $\sigma$ é a velocidade do parâmetro de ajuste que mensura como os erros gerados em um período são corrigidos no período seguinte.

Os resultados da Tabela 1 mostram que as variáveis selecionadas formam um mix de séries temporais com ordem de integração I (0) e I (1), respectivamente, LH e LTXACUM, LTXPFEMP, confirmando que o ARDL é uma técnica adequada. Portanto, dado que a ordem de integração das variáveis é menor que dois, seguiu-se adiante.

Tabela 1: Teste das raízes unitárias ADF

\begin{tabular}{|c|c|c|c|c|c|c|}
\hline \multirow{3}{*}{ Variável } & \multicolumn{4}{|c|}{$\begin{array}{l}\text { Teste estatístico } \\
\text { Intercepto }\end{array}$} & \multirow{3}{*}{$\begin{array}{l}\text { Ordem } \\
\text { de retardo }\end{array}$} & \multirow{3}{*}{$\begin{array}{c}\text { Ordem } \\
\text { de } \\
\text { integração }\end{array}$} \\
\hline & \multicolumn{2}{|c|}{$\begin{array}{c}A D L \\
\text { valores - p }\end{array}$} & \multicolumn{2}{|c|}{$\begin{array}{c}\mathrm{PP} \\
\text { valores - }\end{array}$} & & \\
\hline & Nível & 1a diferença & Nível & 1a diferença & & \\
\hline LTXACUM & 0.3974 & 0.0000 & 0.3264 & ${ }^{*} 0.0000$ & 2 & I (1) \\
\hline LTXPFEMP & 0.3954 & 0.0000 & 0.5916 & $* 0.0000$ & 2 & I (1) \\
\hline $\mathrm{LH}$ & $0.0561 *$ & 0.0000 & 0.2151 & 0.0001 & 1 & $I(0)$ \\
\hline
\end{tabular}

e PP para a estacionariedade das séries

Os resultados apresentados na Tabela 2 revelam que o valor da estatística $\mathrm{F}$ para testar a hipótese conjunta nula de que os coeficientes das variáveis de nível no modelo ARDL são zero (ou seja, não existe nenhuma relação de longo prazo entre eles) é 11.7306. Esse valor fica acima do limite superior tabulado. 
Tabela 2: Técnica de determinação

da relação de longo prazo - ARDL

\begin{tabular}{|c|c|c|}
\hline Intervalos & $\begin{array}{c}\text { Limite Inferior } \\
I(0)\end{array}$ & $\begin{array}{c}\text { Limite Superior } \\
I(1)\end{array}$ \\
\hline $1 \%$ & 5.288 & 6.309 \\
\hline $5 \%$ & 3.793 & 4.855 \\
\hline $10 \%$ & 3.182 & 4.126 \\
\hline Estatística F: 11.7306 & (Prob. 0.022) & \\
\hline
\end{tabular}

Caso: Intercepto sem tendência.

Número de regressores $(K)=2$.

Dados tabulados por Pesaran, Shin e Smith (1996).

As estimativas dos coeficientes de longo prazo com base no modelo ARDL especificada na equação (10) estão sintetizados na Tabela 3. Todas as variáveis estão em logaritmo, portanto, cada coeficiente estimado pode ser interpretado como medidas de elasticidade constante a longo prazo. Um olhar mais atento dos resultados revela que as estimativas variam significativamente em termos de magnitude e os sinais não são contraditórios. No período 1992Q3 à 2012Q4, o valor da taxa de lucro empresarial LTXPFEMP (7.2026) e da profit-share LH (2.0905) são estatisticamente significativos. No subperíodo de 1992Q3 à 2004Q3, a taxa de lucro empresarial não é significativa, assumindo um sinal contrário ao esperado (-.31620). No subperíodo delimitado - 2001Q3 a 2013Q4 - a taxa de lucro assume o sinal esperado e possui novamente um valor significativo. Esses resultados são coerentes com a hipótese de que o investment-profit puzzle causado pela financeirização, e relatado pela literatura internacional, vem interferindo estruturalmente na economia brasileira e que isso se manifestou segundo dois regimes básicos. No primeiro deles, o componente distributivo revela que o domínio da acumulação financeira se centrava ainda numa condição mais profit-led, ou seja, era consistente com uma expansão da renda capitalista na economia, suportando uma moderação salarial. No segundo, padrões distributivos mais favoráveis às rendas salariais tornam a retomada da lucratividade o fator mais importante do crescimento. Contudo, individualmente os dois períodos se contradizem, revelando a inconsistência do nexo investimento-lucro presente nas economias dominadas pela acumulação rentista-financeira (finance dominated-accumulation regime $)^{10} \mathrm{e}$ que podem alternar padrões de crescimento puxados pelas finanças (finance-led growht regime) com padrões claramente bloqueadores do investimento (finance-blocked growth regime).

\footnotetext{
${ }^{10}$ Denominação proposta por Stockhammer (2007) para destacar o fato de que os regimes subordinados às finanças não são sempre finance-led growth. Podem degenerar-se ou afirmarem sua tendência estrutural, ou seja, podem entravar o desenvolvimento sustentado da acumulação produtiva de capital. Neste segundo caso, optamos por denominá-lo por finance-blocked growth regime, padrão que caracteriza agora a economia brasileira e a zona do euro.
} 
Tabela 3: Estimativas dos coeficientes de longo prazo baseada no modelo ARDL

\begin{tabular}{|c|c|c|c|c|}
\hline \multicolumn{5}{|c|}{$\begin{array}{l}\text { Coeficientes de longo prazo } \\
\text { ARDL }(3,1,0) \text { selecionado com base no critério bayesiano de Schwarz } \\
82 \text { observações usadas na estimação de } 1992 \mathrm{Q} 3 \text { a } 2012 \mathrm{Q} 4\end{array}$} \\
\hline Variável dependente: & LTXACUM & Coeficiente & Erro-Padrão & Razão T [Prob] \\
\hline LTXPFEMP & & 1.5150 & .21034 & $7.2026[.000]$ \\
\hline $\mathrm{LH}$ & & 1.4916 & .71350 & $2.0905[.040]$ \\
\hline INPT & & -7.0509 & 2.9577 & $-2.3839[.020]$ \\
\hline \multicolumn{5}{|c|}{51 observações usadas na estimação de 199203 a 200403} \\
\hline Variável dependente: & LTXACUM & Coeficiente & Erro-Padrão & Razão T [Prob] \\
\hline LTXPFEMP & & -.31700 & 1.0025 & $-.31620[.753]$ \\
\hline $\mathrm{LH}$ & & 2.5902 & 1.1792 & 2.1966[.033] \\
\hline INPT & & -10.0152 & 4.5620 & $-2.1953[.033]$ \\
\hline \multicolumn{5}{|c|}{51 observações usadas na estimação de 200103 a 201304} \\
\hline Variável dependente: & LTXACUM & Coeficiente & Erro-Padrão & Razão T [Prob] \\
\hline LTXPFEMP & & 2.0931 & .27897 & 7.5029[.000] \\
\hline LH & & .17453 & .71080 & $.24554[.807]$ \\
\hline INPT & & -2.2402 & 2.9453 & $-.76060[.451]$ \\
\hline
\end{tabular}

Fonte: Elaboração própria.

$\mathrm{Na}$ Tabela 4, o modelo de correção de erros, estimado utilizando o critério bayesiano de Schwarz, evidencia que todos os coeficientes são estatisticamente significativos, além de passar de maneira aceitável segundo os testes de diagnóstico. O coeficiente de correção de erros estimado em -.17308 (.043769) é altamente significativo do ponto de vista estatístico, possui o sinal correto esperado, e sugere uma velocidade moderada de convergência ao equilíbrio. Nessa perspectiva, o alto coeficiente (em valor absoluto) indica o rápido retorno da economia para o equilíbrio após o choque. Esse modelo foi utilizado para projetar a taxa de acumulação condicional presente, sob os impactos pretéritos da taxa de lucro empresarial e da profit-share. No Gráfico 8, o declínio da taxa acumulação apresenta-se como um processo tendencial desde o último trimestre de 2010 e persiste ao longo das subsequentes conjunturas econômicas. 
Tabela 4: Representação da Correção de Erros pelo Modelo ARDL

\begin{tabular}{|c|c|c|c|}
\hline \multicolumn{4}{|c|}{ ARDL (3,1,0) selecionado com base no critério bayesiano de Schwarz } \\
A variável dependente é dLTXACUM \\
82 observações usadas na estimação de 199203 a 201204 \\
\hline Regressor & Coeficiente & Erro-Padrão & Razão - T[Prob] \\
\hline dLTXACUM1 & .36314 & .083527 & $4.3476[.000]$ \\
dLTXACUM2 & -.30445 & .081995 & $-3.7131[.000]$ \\
dLTXPFEMP & .49354 & .064134 & $7.6954[.000]$ \\
dLH & .25817 & .13345 & $1.9346[.057]$ \\
dINPT & -1.2204 & .56582 & $-2.1568[.034]$ \\
ecm(-1) & -.17308 & .043769 & $-3.9545[.000]$ \\
\hline
\end{tabular}

Fonte: Elaboração própria.

Gráfico 8: Projeção dinâmica para mudanças na taxa de acumulação - Brasil 199203 - 201304

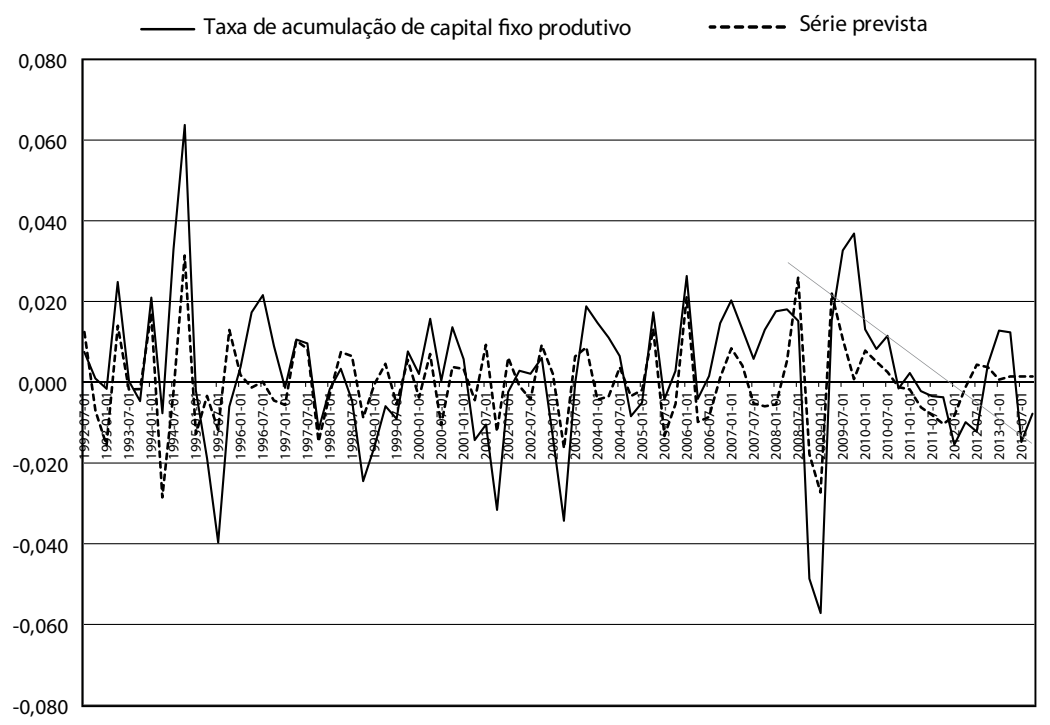

Fonte: Elaboração própria. 


\section{CONCLUSÃO}

"A existência de poupança corrente externa às firmas, realizadas por pessoas que vivem de renda, tende a deprimir o investimento e, consequentemente, reduzir o desenvolvimento no longo prazo."

(Michal Kalecki, Teoria da Dinâmica Econômica, 1985, p. 184)

A crise norte-americana de 2008 se propagou rapidamente pela economia mundial e seu impacto sobre a economia brasileira tornou-se patente em 2009. A análise do comportamento da taxa de lucro geral é um indicador fundamental nos estudos das crises estruturais e permite inferir as seguintes conclusões: a) apesar de as políticas governamentais de expansão do crédito direcionado terem impedido uma recessão mais grave nesse ano, não foram capazes de conter a deterioração da conjuntura macroeconômica que se afirmaria nos anos subsequentes; b) as desonerações fiscais não surtiram os efeitos esperados porque a tendência de queda da taxa de lucro se afirmou em 2011, precisamente num momento em que as políticas de estímulos foram removidas pelo governo, através da adoção de medidas de cunho macroprudencial pelo canal tradicional da política monetária do Banco Central. Tais medidas visavam diminuir a liquidez e conter a expansão do crédito, cujo efeito sobre a demanda agregada durante o ano de 2011 foi restritivo, além dos ajustes fiscais anunciados e implementados entre 2011 e 2012. Gerou-se um ciclo de contração fiscal, apesar da existência de um possível alívio do ciclo de restrição via juros; c) de 2000 a 2005, as taxas de lucro da economia norte-americana e brasileira mantiveram-se em crescimento. A crise de 2008-2009 provocará a desconexão dessas variáveis, o que pode ser atribuído às políticas econômicas divergentes nesses países. Basicamente, os EUA mobilizaram políticas anticíclicas de maneira mais consistente e duradoura do que o realizado pelo Brasil, excessivamente preocupado na manutenção de superávits fiscais primários e na fixação das taxas de juros em níveis muito acima dos padrões internacionais; d) em linhas gerais, comparativamente à economia norte-americana, as taxas de acumulação e de lucro na economia brasileira são mais elevadas, o que é esperado para um país ainda em desenvolvimento. Mas, diferentemente do caso brasileiro, a economia norte-americana apresenta uma retomada do crescimento da taxa de acumulação, a partir de 2011, e da participação dos salários no PIB, a partir de 2014.

De modo geral, a contração fiscal de 2011, quando o investimento público e das estatais acusaram uma queda real, respectivamente, de $12 \%$ e $8,6 \%$, combinou-se com outras medidas contracionistas, o que teve um efeito pró-cíclico na intensa desaceleração da economia brasileira, em um ambiente de franco declínio da demanda interna e externa. Entretanto, a persistente atonia do crescimento da economia brasileira, seja por fatores de oferta e de demanda, ensejou mudanças de rumo ainda no terceiro trimestre de 2011, reiniciando um ciclo de redução da taxa Selic e reduzindo as medidas macroprudenciais adotadas. A reorientação da política governamental pretendia evitar o ingresso da atividade econômica num círcu- 
lo vicioso que viesse a interferir na dinâmica do mercado de trabalho e a deprimir a demanda. Entretanto, a despeito dos esforços governamentais, o crescimento econômico declina de 2,7\% para 1,0\% em 2012 .

Contrariamente à visão ortodoxa, o exame do comportamento tendencial das taxas de lucro e de acumulação, imediatamente após o impacto da crise norte-americana em 2009, aponta para a reafirmação de fatores estruturais, característicos da economia brasileira atual, que não poderiam ser contidos por medidas de curto prazo de estímulo ao investimento e à demanda agregada. Dentre esses fatores, destacam-se os baixos ganhos de produtividade do trabalho e o declínio da produtividade do capital, decorrentes do atual processo de desindustrialização do país. Essas tendências permaneceram ao mesmo tempo em que os salários reais cresciam e a taxa média de lucro bruto empresarial declinava. A partir de 2012, conjugam-se com o fim do boom dos preços internacionais das commodities, o que reforçou ainda mais a piora das expectativas de lucro empresarial quanto às decisões de investimento. A crise fiscal torna-se manifesta em função da rápida deterioração do crescimento econômico e não do caráter supostamente perdulário do Estado brasileiro. Pelo contrário, no que concerne aos gastos sociais, as despesas têm permanecido perversamente aquém dos níveis necessários à plena satisfação das demandas da sociedade. A análise da situação fiscal deve, portanto, voltar-se para as despesas financeiras, impostas e reproduzidas no Brasil pelas estruturas da financeirização pela renda de juros.

\section{REFERÊNCIAS BIBLIOGRÁFICAS}

AGLIETTA, Michel. Macroéconomie financière. La Découvert, Paris, 1995.

BHADURI, Amit; MARGLIN, Stephen (1990) "Unemployment and the real wage: the economic basis for contesting political ideologies". Cambridge Journal of Economics, v. 14, n. 4, p. 375-393.

MARGLIN, Stephen A.; BHADURI, Amit (1991). Profit Squeeze and Keynesian Theory. Palgrave Macmillan UK.

BOYER Robert. (2000) "Is a finance-led growth regime a viable alternative to Fordism? A preliminary analysis", Economy and Society, Vol. 29, n 1, February, p. 111-145.

BOYER Robert. (2012) What we learned from the 2009 financial crises in the emerging countries. Paper prepared for the conference "Financial Stability and Growth" São Paulo, March 22-23.

BOYER Robert (2011) "Les financiers détruiront-ils le capitalisme? " Economica.

BRUNO, M. (2014) "Desafios do desenvolvimento socioeconômico brasileiro: uma perspectiva institucionalista do periodo recente". In O Panorama Socioeconômico do Brasil e suas relações com a Economia Social de Mercado. Fundação Konrad Adenauer.

BRUNO, M. (2007) "Financiarisation et accumulation du capital produtif au Brésil. Les obstacles macroécomiques à une croissance soutenue“. Revue Tiers Monde n. 189 - janvier-mars.

BRUNO, M.(2011) "Financeirização e crescimento econômico no Brasil“. Revista ComCiência. SBPC.

BRUNO, M. e CAFFE, Ricardo. Indicadores macroeconômicos de financeirização: metodologia de construção e aplicação ao caso do Brasil. In Miguel Bruno (org.). População, Espaço e Sustentabilidade: contribuições para o desenvolvimento do Brasil. IBGE, 2015.

BRUNO, M. et al. (2011) "Finance-led growth regime no Brasil: estatuto teórico, evidências empíricas e consequências macroeconômicas”. Revista de Economia Política, vol. 3 n. 5(125). Edição Especial.

DATHEIN, Ricardo (2011) "Crise econômica e taxa de lucro nos EUA". Revista de Econ. Contempor. V. 15 n. 2. 
DATHEIN, Ricardo (2007) Crescimento, Investimento e Taxa de Lucro na Economia Brasileira, Anpec Sul.

DUMÉNIL, G. e LÉVY, D. (2014) A Crise do Neoliberalismo. Boitempo.

KALECKI, Michal (1985) Teoria da Dinâmica Econômica: ensaio sobre as mudanças cíclicas e a longo prazo da economia capitalista, $2^{a}$ ed. São Paulo, Nova Cultural.

KEYNES, John Maynard (2016) General Theory of Employment, Interest and Money. Atlantic Publishers \& Dist.

MARQUETTI, A. A economia brasileira no capitalismo neoliberal: progresso técnico, distribuição de renda e mudança institucional. http://raceadmv3.nuca.ie.ufrj.br/buscarace/Docs/aamarquetti4. pdf

MARQUETTI, A. MALDONADO, E. F. \& LAUTERT, V. (2010) "The rate of profit in the Brazilian economy, 1953-2003". Review of Radical Political Economics, 42(4) 485-504.

MARX. Karl (2012) Salário, Preço e Lucro. Expressão popular.

MIEBACH, A. D. (2015) “Trajetória recente da taxa de lucro". FEE-Carta de Conjuntura, Ano 24 - n. 8.

PALLEY, Thomas (2007) Financialization: what it is and why it matters. Working paper no. 525. The Levy Economics Institute of Bard College.

PESARAN, M. Hashem; SHIN, Yongcheol (1998)." An autoregressive distributed-lag modelling approach to cointegration analysis". Econometric Society Monographs, v. 31, p. 371-413.

PESARAN, M.H., SHIN, Y.C. and SMITH, R.J. (2001) "Bounds testing approaches to the analysis of level relationships”, Journal of Applied Econometrics, vol. 16, no. 3, pp. 289-326

ROCCA, C. A. e SANTOS JR. L. M. (2014) Redução da taxa de poupança e o financiamento dos investimentos no Brasil: 2010-2013. Centro de Estudos do IBMEC.

ROSIER, Bernard (1993). Les théories des crises économiques. La Découverte, Repères, Paris, 1993.

STOCKHAMMER, E. (2004) "Financialization and slowdown of accumulation". Cambridge Journal of Economics, n. 28, p. 719-741, 2004.

STOCKHAMMER, E. (2007). "Some stylized facts on the finance-dominated accumulation regime". Working paper series. Political Economy Research Institute-PERI, 2007.

VAN TREECK, Till (2008) "Reconsidering the investment-profit nexus in finance-led economies: an ardl-based approach." Metroeconomica, v. 59, n. 3, p. 371-404.

UEMURA, H. (2000) "Growth, distribution and structural change in the post-war Japanese in Japanese capitalism in crisis - a regulationist interpretation", in $\mathrm{R}$. Boyer and Toshio Yamada, eds. Routledge Advances in International Political Economy, London, USA, Canada.

\section{APÊNDICE I - NOTAS SOBRE A METODOLOGIA DE ANÁLISE EMPÍRICA}

Uma estratégia de análise empírica através da metodologia ARDL (autoregressive distributed lag) oferece pistas bem promissoras nessa direção. Como foi discutido até aqui, existem evidências de que as relações de longo prazo entre a taxa de acumulação e a taxa de lucro macroeconômica venham se modificando por conta de transformações estruturais que ocorreram na economia brasileira. Uma forma de captar este impacto é proporcionada pelo modelo empírico baseado em Van Treeck (2008), que utiliza versões lineares tradicionais da função de investimento, presentes no modelo de Cambridge e no modelo de Bhaduri-Marglin (1990). Com isso, torna-se possível captar os efeitos da lucratividade e da distribuição funcional da renda, via profit-share, sobre a acumulação de capital fixo produtivo. A equação (6) mostra o modelo. 
Onde: TXACUM = taxa de acumulação de capital fixo produtivo; TXPFEMP = taxa de lucro empresarial, ou seja, a taxa de lucro macroeconômica líquida da renda financeira; e $\mathrm{H}=$ a profit-share da economia. Os dados trimestrais para as variáveis foram obtidos junto ao IBGE e ao IPEADATA, e foram tratados sazonalmente quando necessário.

No sentido de obter uma função linear estimável mais explícita para a equação (6), as variáveis foram transformadas em logs (L) para alcançar a forma seguinte:

$$
L T X A C U M=\alpha+\delta 1 L T X P F E M P+\delta 2 L H+\varepsilon
$$

Os coeficientes estimados nesse caso são interpretados como elasticidades constantes que capturam a sensibilidade da variável dependente relativamente às variações unitárias das variáveis explicativas. Com efeito, espera-se que LTXACUM seja mais do proporcionalmente sensível às variações das variáveis explanatórias, ceteris paribus.

O teste de cointegração (bound testing ou teste de fronteira) de Pesaran, Shin e Smith (2001), que é baseado em uma estrutura ARDL é empregado para examinar a relação de longo prazo entre as taxas de acumulação e de lucro empresarial da economia brasileira. $\mathrm{O}$ uso da abordagem de ARDL é conveniente e consistente para amostras de pequeno tamanho e a robustez relativa dessa técnica deve-se à sua capacidade de estabelecer relações de cointegração, mesmo que os regressores sejam de ordem $\mathrm{I}(0)$ e/ou $\mathrm{I}(1)$. Além disso, o procedimento permite evitar os problemas associados com análise de cointegração tradicional que requer a classificação das variáveis em I(0) e I $(1)$.

Existem duas etapas envolvidas no procedimento ARDL. Para começar, a estatística F é empregada para testar a significância dos níveis defasados das variáveis na forma de um modelo com correção de erro do ARDL subjacente, ao mesmo tempo em que é utilizada para determinar a existência de uma relação de longo prazo entre as variáveis sob investigação. Apesar da natureza não padrão da distribuição assintótica da estatística $\mathrm{F}$ calculada, independentemente do fato dos regressores serem de ordem de integração distinta, Pesaran, Shin e Smith (1996) tabularam os valores críticos apropriados para diferentes números de regressores (k) que podem ser empregados na realização das estimações.

Após a confirmação da cointegração passa-se para a busca do melhor modelo por meio de critérios de seleção como AIC (Akaike Information Criterion) e BIC (Bayesian Information Criterion) e o SBC (Schwarz Bayesian Criterion). Com a seleção do melhor modelo, calculam-se os coeficientes de longo prazo. A hipótese nula é a da não existência de uma relação de longo prazo entre as variáveis:

$H_{0}: \lambda_{1}=\lambda_{2}=\lambda_{3}=0$ (nenhuma relação de longo prazo), contra

$$
H_{1}: \lambda_{1} \neq \lambda_{2} \neq \lambda_{3} \neq 0 \text { (há uma relação de longo prazo) }
$$


Se houver uma relação de longo prazo satisfatória entre as variáveis a serem estimadas, a etapa posterior será a estimação dos coeficientes das relações de longo prazo com as inferências sobre seus valores. O modelo de correção de erro associado com as estimativas de longo prazo pode ser estimado para determinar a estabilidade da relação de longo prazo. Esta relação hipotética apresentada na equação (7) é capturada com precisão no modelo autorregressivo generalizado com defasagens distribuídas na forma ARDL $\left(\mathrm{p} ; \mathrm{q}_{1} ; \mathrm{q}_{2} ; \ldots, \mathrm{q}_{\mathrm{k}}\right)$. De tal modo que:

$$
\begin{aligned}
& \delta(L, p) y_{t}=\sum_{i=1}^{k} \gamma_{i}\left(L_{i} q_{i}\right) x_{i t}+\delta w_{t}+u_{t} \\
& \delta(L, p)=1-\delta_{1} L+\delta_{2} L^{2}-\cdots-\delta_{p} L^{p}+u_{t} \\
& \gamma_{i}\left(L_{i} q_{i}\right)=1-\gamma_{i 1} L+\gamma_{i 2} L^{2}+\cdots+\gamma_{i q i} L^{q i} \quad \text { para } \mathrm{i}=1,2, \ldots, \mathrm{k} .
\end{aligned}
$$

Se $\delta(L, p)=1$, então o modelo não possui nenhuma defasagem de $y_{t}$ e a equação é reduzida ao modelo de defasagens distribuídas. L é o operador defasado tal que $L y_{t}=y_{t-1}$ e $w_{t}$ é um vetor de variáveis determinísticas, tais como o termo de intercepto, dummies sazonais ou tendências, ou variáveis exógenas com defasagens fixas. 